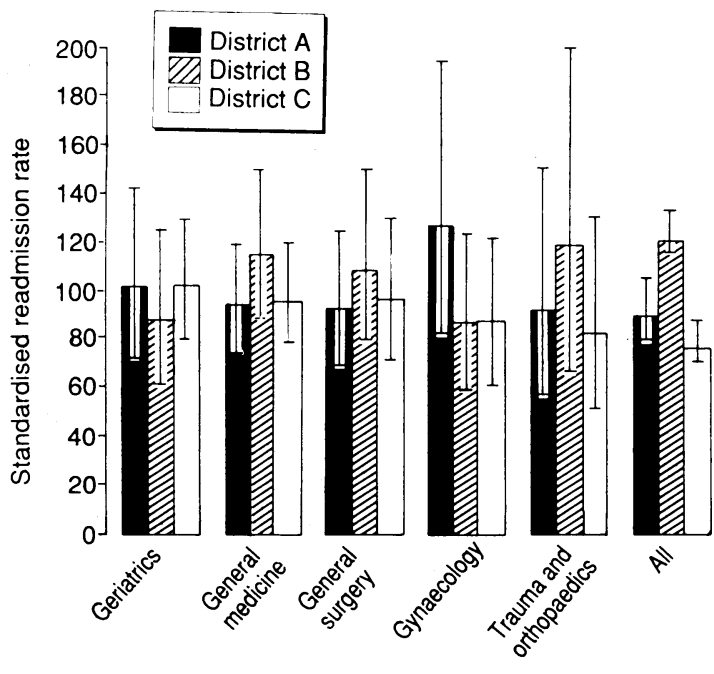

Specialty

FIG 6-Readmission rates at 28 days directly standardised for age group and sex for three districts by acute specialty, 1988 (standard differs for each specialty). Bars are $95 \%$ confidence intervals

Readmission rate at 28 days for general surgery directly standardised for age group and sex by consultant in district $A, 1988$

\begin{tabular}{lccc}
\hline & $\begin{array}{c}\text { Standardised } \\
\text { readmission rate }\end{array}$ & $\begin{array}{c}\text { No of } \\
\text { readmissions }\end{array}$ & $\begin{array}{c}95 \% \text { Confidence } \\
\text { interval }\end{array}$ \\
\hline Consultant 1 & 69 & 23 & 36 to 135 \\
Consultant 2 & 113 & 65 & 60 to 213 \\
Consultant 3 & 104 & 78 & 62 to 177 \\
Consultant 4 & 107 & 24 & 39 to 296 \\
\hline All & 100 & 190 & \\
\hline
\end{tabular}

rates that we found must reflect different readmission thresholds. The propensity to readmit might be predicted to correspond with increasing age and the perceived frailty of patients in older age groups. But the difference relating to sex remains more difficult to interpret.

There were appreciable differences among the readmission rates in different specialties with those in surgical specialties being lower than in medical specialties (for example, general surgery $4 \cdot 1 \% v$ geriatric medicine $15 \cdot 1 \%$ ). This finding fits with known differences of case mix and severity. General medical patients commonly have more than one illness or problem and have more chronic conditions, both of which might result in an increased likelihood of readmission. The readmission rates at 28 days are similar to those found in the Oxford record linkage study. Surprisingly, for each specialty the differences in readmission rates among districts were not significant once the rates were standardised for age and sex. This suggests that reliable annual comparisons between districts will require data aggregated from more than one specialty. Furthermore, it should be remembered that similar specialties in different districts are liable to have differences of case mix and severity that systematically affect the readmission rates. This effect was not examined here but will need to be considered if rates are to be compared reliably. Differences among readmission rates for individual consultants within the same specialty over a year are likely to be based on too few events to allow reliable comparisons. Data aggregated over several years would give larger numbers for comparison but would result in less timely feedback and mask short term trends.

To summarise, although certain difficulties were encountered, readmission rates may be measured with routinely collected health service data. They require standardisation for age and sex as readmission is more likely in male patients and in older age groups. Readmission rates showed a decay pattern with time that was specialty specific; surgical readmission rates were lower than medical readmission rates. Statistically valid annual comparisons of readmission rates may be made among districts only for combinations of specialties. Routine comparisons at the level of individual consultants or specialties, however attractive, are inadvisable.

We thank Tad Matus, who was closely concerned with the early stages of this work, and Ruaridh Milne, Nick Black, and Mark McCarthy for their comments and suggestions.

1 Secretaries of State for Health, Wales, Northern Ireland, and Scotland. Working for patients. Framework for information systems: information. London: HMSO, 1990. (Annex 13, District Information Requirements.)

2 Mills I. Outcome measures-getting there. Health Service fournal 1987 July $16: 882$

3 Health Services Indicator Group. A report on Kömer indicators. London: Department of Health, 1988

4 West RR. Interpreting government statistics on acute hospital care. BMF 1987:295:509-10.

5 Henderson J, Goldacre MJ, Graveney MJ, Simmons HM. Use of medical record linkage to study readmission rates. BMF 1989;299:709.

6 Goldacre M, Simmons H, Henderson J, Gill LE. Trends in episode based and person based rates of admission to hospital. BMF 1988;296:583-5.

7 Roos LL, Cageorge SM, Austen E, Lohr K. Using computers to identify complications after surgery. Am f Public Health 1985;75:1289-95.

8 Anderson GF, Steinberg EP. Hospital readmissions in the Medicare population. $N$ Engl f Med 1984;311:1349-53.

victor CR, Vetter NJ. The early readmission of the elderly to hospital. Age Aging 1985;14:37-42.

10 Fethke CC, Smith IM, Johnson N. Risk factors affecting readmission of the elderly. Med Care 1986;24:429-37.

11 Gooding J, Jette AM. Hospital readmissions among the elderly. I Am (ieriatr Soc 1985;33:595-601.

(Accepted 4 fuly 1990

\title{
Are readmissions avoidable?
}

\author{
Aileen Clarke
}

Health Service Research Unit, London School of Hygiene and Tropical Medicine, London WC1E 7HT

Aileen Clarke, MRCGP, senior registrar

\begin{abstract}
Objective-To examine the possible use of readmission rates as an outcome indicator of hospital inpatient care by investigating avoidability of unplanned readmissions within 28 days of discharge.

Design-Retrospective analysis of a stratified random sample of case notes of patients with an unplanned readmission between July 1987 and June 1988 by nine clinical assessors ( 263 assessments) and categorisation of the readmission as avoidable, unavoidable, or unclassifiable.
\end{abstract}

Setting-District in North East Thames region.
481 General medical, geriatric, and general surgical inpatients with a readmission at 0-6 days or 21-27 days after the first (index) discharge between July 1987 and June 1988 from whom 100 case notes were selected randomly and of which 74 were available for study.

Main outcome measures-Assessment of readmissions as avoidable, unavoidable, unclassifiable, variability of assessment within cases and variability among assessors according to specialty and duration to readmission.

Results-General medical and geriatric readmis- 
sions and surgical readmissions at 0-6 days after discharge were more likely to be assessed as avoidable than those at 21-27 days (medical readmissions $32 v 6 \%$, surgical admissions $49 v 19 \%$ ). General surgical readmissions were significantly more frequently assessed as avoidable than general medical and geriatric readmissions. The extent of agreement between doctors varied, with general medical and geriatric readmissions at 21-27 days after first discharge causing the greatest variability of judgment.

Conclusions-Differences were apparent in the extent of avoidability of readmissions in different groups of admissions. However, assessors rated only $49.3 \%$ of the group with the highest proportion of avoidable admissions (surgical readmissions at 0-6 days) as avoidable. The remainder were thought to be unavoidable except for $2 \%$, which could not be classified. The use of readmission rates as an outcome indicator of hospital inpatient care should be avoided.

\section{Introduction}

If readmission rates are to be used as an outcome indicator it is necessary to show that a high proportion of readmissions would have been avoidable if a better quality of hospital care had been received. Various authors have attempted to measure avoidability of readmissions (table I). Eleven per cent of medical and surgical readmissions, ${ }^{1} 48 \%$ of geriatric readmissions, ${ }^{2}$ and up to $77 \%$ of surgical readmissions after hysterectomy ${ }^{3}$ were considered avoidable. However, variable definitions for readmission were used, and the differing results are not surprising.

This study concerns unplanned readmissions to hospital at fewer than 28 days after an index discharge. (The basis for this definition is explained in the previous paper. ${ }^{6}$ )

\section{Methods}

The study was performed in an outer London district in North East Thames region. The Körner reporting system was used to generate a list of case note numbers of general medical, geriatric, and general surgical patients who had an unplanned readmission between July 1987 and June 1988 after a planned or unplanned first admission. A random sample of 100 case note numbers was selected from a sampling frame of 481 patients with unplanned readmissions that occurred at 0-6 days or 21-27 days after discharge in the selected specialties; case notes for general medical and geriatric patients were selected and analysed together (table II). Those parts of the case notes relating to both admissions were copied and the identity of the patient and his or her clinical attendants were masked. The copies were circulated to teams of assessors, who were asked to assess the avoidability of the second admission with respect to the hospital care given in the first admission. The teams included senior and junior general surgeons, general physicians, and public health physicians, and there were five medical and four surgical assessors. They were asked to classify the readmissions as avoidable, unavoidable, and unclassifiable according to a classification scheme provided to

TABLE I - Summary of avoidable readmissions in five studies

\begin{tabular}{|c|c|c|c|c|}
\hline Study & $\begin{array}{l}\text { Category of } \\
\text { patients }\end{array}$ & Follow up & $\begin{array}{l}\text { No of } \\
\text { readmissions }\end{array}$ & $\begin{array}{l}\% \text { Avoidable } \\
\text { readmissions }{ }^{\star}\end{array}$ \\
\hline Graham and Livesley' & Elderly & 1 Year & 153 & 48 \\
\hline McInnes et al $l^{2}$ & Elderly & 4 Months & 153 & 30 \\
\hline Popplewell et $a l^{3}$ & General medical & Up to 2 months & 73 & 18 \\
\hline McDowell et al & Medical and surgical & 3 Months & 78 & 11 \\
\hline Roos et al & After hysterectomy & 1 Month & 199 & 77 \\
\hline
\end{tabular}

«Not common method for assessing avoidability.
TABLE II-Case notes of patients studied according to specialty and duration to readmission after discharge

\begin{tabular}{|c|c|c|c|}
\hline $\begin{array}{l}\text { Duration to } \\
\text { readmission after } \\
\text { discharge (days) }\end{array}$ & $\begin{array}{c}\text { Sampling } \\
\text { frame }\end{array}$ & $\begin{array}{c}\text { No of case notes } \\
\text { selected }\end{array}$ & $\begin{array}{c}\text { No of case notes } \\
\text { available }\end{array}$ \\
\hline \multicolumn{4}{|c|}{ General medical and geriatric patients } \\
\hline $0-6$ & 207 & 25 & 18 \\
\hline $21-27$ & 166 & 25 & 19 \\
\hline \multicolumn{4}{|c|}{ Surgical patients } \\
\hline $0-6$ & 60 & 25 & 19 \\
\hline $21-27$ & 48 & 25 & 18 \\
\hline Total & 481 & 100 & 74 \\
\hline
\end{tabular}

TABLE III-Assessments of avoidability of readmission according to specialty and duration to readmission after discharge

\begin{tabular}{|c|c|c|c|}
\hline $\begin{array}{l}\text { Duration to } \\
\text { readmission after } \\
\text { discharge (days) }\end{array}$ & $\begin{array}{l}\% \text { Avoidable } \\
\text { readmissions }\end{array}$ & $\begin{array}{c}\text { No of } \\
\text { assessments }\end{array}$ & $\begin{array}{c}95 \% \text { Confidence } \\
\text { interval }\end{array}$ \\
\hline \multicolumn{4}{|c|}{ General medical and geriatric patients } \\
\hline $0-6$ & $31 \cdot 5$ & 54 & $19 \cdot 1$ to 43.9 \\
\hline $21-27$ & $6 \cdot 3$ & 84 & 1.0 to 11.7 \\
\hline Total & $16 \cdot 5$ & 133 & 10.9 to 22.8 \\
\hline \multicolumn{4}{|c|}{ Surgical patients } \\
\hline $0-6$ & $49 \cdot 3^{\circ}$ & 67 & $37 \cdot 3$ to $61 \cdot 3$ \\
\hline $21-27$ & $19 \cdot 0$ & 63 & $9 \cdot 3$ to $28 \cdot 7$ \\
\hline Total & $34 \cdot 6$ & 130 & $26 \cdot 4$ to $42 \cdot 8$ \\
\hline
\end{tabular}

help their decisions (box). The assessments were performed individually. All of the available sample was seen by two assessors, and half of the sample was seen by four assessors or more.

\section{Analysis}

The avoidability of readmissions at 0-6 days after discharge was compared with that of readmissions at 21-27 days, and $95 \%$ confidence intervals were calculated for the proportions of avoidable readmissions with the binomial approximation to the normal distribution. Avoidability of readmissions in general medical and geriatric patients was compared with that in surgical patients, and variability within cases and among observers in assessing avoidability was analysed.

\section{Results and discussion}

Of the sample of 100 case notes, 74 were available for further investigation (table II) and 263 assessments were made of them. In all, 259 (98\%) of the assessments classified cases as avoidable or unavoidable, with the remainder (four assessments) being unclassified.

\section{Classification scheme for assessing readmissions ${ }^{\star}$ \\ Unavoidable}

-Chronic or relapsing disorder; care at home desirable if possible. Unavoidable complication

- Readmission for social or psychological reason. Reasons probably beyond control of hospital services (may include compliance)

-Completely different diagnosis from previous admission.

Avoidable

- Recurrence or continuation of disorder leading to first admission

- Recognised avoidable complication

- Readmission for social or psychological reason. Reasons probably within control of hospital services (may include compliance).

Unclassifiable

${ }^{\star}$ Derived in part from Graham and Livesley ${ }^{\prime}$ 


\begin{tabular}{|c|c|c|c|c|c|c|}
\hline \multirow[b]{2}{*}{ Case No } & \multirow[b]{2}{*}{ Age/sex } & \multirow{2}{*}{$\begin{array}{c}\text { Duration to } \\
\text { readmission } \\
\text { after } \\
\text { discharge }\end{array}$} & \multicolumn{2}{|l|}{ Diagnosis } & \multirow{2}{*}{$\begin{array}{c}\text { Overall } \\
\text { assessment }\end{array}$} & \multirow[b]{2}{*}{ Comment } \\
\hline & & & At first admission & At second admission & & \\
\hline 1 & $65 \mathrm{~F}$ & 4 days & $\begin{array}{l}\text { Ischaemic heart disease, chest infection, } \\
\text { and untreated hypothyroidism }\end{array}$ & $\begin{array}{l}\text { Congestive heart } \\
\text { failure }\end{array}$ & Avoidable & $\begin{array}{l}\text { Readmission probably avoidable if } \\
\text { hypothyroidism had been treated }\end{array}$ \\
\hline 2 & $74 M$ & 2 days & $\begin{array}{l}\text { Subendocardial infarct. Serious aortic } \\
\text { stenosis }\end{array}$ & $\begin{array}{l}\text { Collapse } \\
\text { ?Arrhythmias }\end{array}$ & Mixed & $\begin{array}{l}\text { ?Calculated risk. Assessed as "well } \\
\text { today" by discharging doctor }\end{array}$ \\
\hline 3 & $23 \mathrm{M}$ & 6 days & Removal of anal warts and warts in groin & Wound infection & Avoidable & $\begin{array}{l}\text { Mixture of "clean" and "dirty" surgery, } \\
\text { but two anaesthetic procedures } \\
\text { avoided }\end{array}$ \\
\hline 4 & $61 \mathrm{~F}$ & 1 day & $\begin{array}{l}\text { Cholecystectomy repair. Fever on } \\
\text { discharge. Instructed to return if unwell }\end{array}$ & $\begin{array}{l}\text { Probable chest } \\
\text { infection }\end{array}$ & Mixed & $\begin{array}{l}\text { Disagreement among assessors whether } \\
\text { calculated risk was acceptable or } \\
\text { unacceptable }\end{array}$ \\
\hline 5 & $42 M$ & 26 days & Carcinoma oesophagus for dilatation & $\begin{array}{l}\text { Jaundice, carcinoma } \\
\text { oesophagus }\end{array}$ & Unavoidable & Recognised unavoidable complication \\
\hline 6 & $11 M$ & 23 days & $\begin{array}{l}\text { Right ischiorectal abscess. No underlying } \\
\text { cause found }\end{array}$ & $\begin{array}{l}\text { Left ischiorectal } \\
\text { abscess }\end{array}$ & Unavoidable & Unlucky \\
\hline
\end{tabular}

TABLE V - Variability of assessment within cases $(n=74)$ according to intraclass correlation coefficient

\begin{tabular}{|c|c|c|c|}
\hline $\begin{array}{l}\text { Duration to } \\
\text { readmission } \\
\text { after discharge } \\
\text { (days) }\end{array}$ & $\begin{array}{l}\text { Intraclass } \\
\text { correlation } \\
\text { coefficient }\end{array}$ & $F$ value & $\mathrm{p}$ Value \\
\hline \multicolumn{4}{|c|}{ General medical and geriatric patients } \\
\hline $0-6$ & $0 \cdot 48$ & $F 17,30=3 \cdot 43$ & $<0.05$ \\
\hline $21-27$ & 0.07 & $F 18,61=1 \cdot 35$ & NS \\
\hline \multicolumn{4}{|c|}{ Surgical patients } \\
\hline $0-6$ & $0 \cdot 15$ & $F 18,47=1.62$ & $<0 \cdot 1$ \\
\hline $21-27$ & $0 \cdot 55$ & $F 17,44=5.53$ & $<0.05$ \\
\hline
\end{tabular}

Table III shows the results of the assessments of avoidability of readmissions at 0-6 days and 21-27 days after discharge and table IV gives examples of details of some cases and the assessments of avoidability. The extent to which the same cases were judged differently by different assessors was examined with intraclass correlation coefficients (table V), ${ }^{7}$ which are of value when there is a different number of assessors per case. Higher values indicate a greater degree of agreement. Variability among observers was measured with $\chi^{2}$ tests (table VI), the lower the value the greater the agreement.

The assessors identified "calculated risk" as an important cause for readmission and suggested that patients were commonly allowed home early to see whether they would manage, having been told of any complications to be aware of.

Of the 100 case notes selected for study seven were found to have been miscoded because they did not refer to a readmission, the patient was from the wrong specialty, or transfer of a patient had been wrongly coded as a readmission. This underlines the fact that use of readmission rates as an outcome indicator will partly reflect differences in the quality of data collection among different districts.

The assessors found surgical readmissions significantly more avoidable than medical readmissions, confirming previous research. Further, readmissions within 0-6 days were found to be significantly more avoidable than those within 20-27 days. Although such a finding might be predicted, it has not previously been reported. The extent of agreement between assessors varied, with readmissions of medical patients at 21-27 days after discharge causing the most disagreement. This might be predicted: the presence of multiple conditions is common in general medical and geriatric patients and is likely to make the reasons for readmission at up to a month after discharge from hospital difficult to disentangle. The category "unclassifiable" was seldom used, suggesting that mostly assessors were able to rate a readmission according to its avoidability. However, the number of avoidable readmissions found was lower than in some other studies ${ }^{5}$ and might have been increased by using more independent assessors.

The pattern of hospital care is changing ${ }^{8}$ with a good use of hospital beds entailing shorter length of stay and a recognition of the ability of patients to care for themselves. In the district studied, as elsewhere, clinicians are apparently starting to encourage responsibility and self care by allowing patients home earlier than they might otherwise have done, on condition that they return if their condition deteriorates. This practice raises the rate of unplanned readmissions and would be much less used if readmission rate were introduced as an indicator of outcome.

The few avoidable readmissions found, even in early surgical readmissions, suggests that trying to reduce a readmission rate by improving the standard of care given may have little effect. The findings suggest that the use of readmission rate as an outcome indicator of hospital inpatient care should be avoided.

I thank Tad Matus, Ruaridh Milne, Mark McCarthy, and Nick Black for their encouragement and helpful comments, and Angela Wade, department of community medicine, University College, London, for statistical advice. This work was partly supported by a grant from the Department of Health.

1 Graham $\mathrm{H}$, Livesley B. Can readmissions to a geriatric medical unit be prevented? Lancet 1983;i:404-6.

McInnes EG, Joshi DM, O'Brien TD. Failed discharges: setting standards for improvement. Geriatric Medicine 1988; April:35-45.

3 Popplewell PY, Chalmers JP, Miller CDJ, Rayner PY. A review of early medical readmissions at the Flinders Medical Centre. Aust Clin Rev 1984;March:3-5. McDowell NM, Hunter SA, Ludke RL. Readmissions to a veterans' adminiscDowell NM, Hunter SA, Ludke RL. Readmissions to a vetera
tration medical centre. Fournal of Quality Assurance 1985;7:20-3.

tration medical centre. Fournal of Quality Assurance 1985;7:20-3.
5 Roos LL, Cageorge SM, Austen E, Lohr K. Using computers to identify Roos LL, Cageorge SM, Austen E, Lohr K. Using computers
complications after surgery. Am f Public Health 1985;75:1289-95.

6 Chambers SM, Clarke A. Measuring readmission rates. BMf 1990;301:1134-6. 7 Bartko JJ, Carpenter WT. On the methods and theory of reliability testing. J Nerv Ment Dis 1976;163:307-17.

8 Ham C, Costain D, Benzeral M. New horizons in acute care. London: NAHA, 1989.

(Accepted 4 fuly 1990) 